\title{
Catalytic Efficiency of Heteropoly 11-Tungsto-1-Vanadophosphoric Acid - Activated Clay in the Condensation Reaction of Thiourea with 4-Chlorobenzaldehyde
}

\author{
K. Selvakumar, A. Raja, M. Arunpandian, P. Sami, M. Swaminathan
}

\begin{abstract}
Catalytic efficiency of the heteropoly 11-tungsto-1-vanadophosphoric acid (HPV) supported on activated natural clay (HPVAC) towards condensation reaction of thiourea with 4-chlorobenzaldehyde to form (1E,3Z)-1,3-bis(4-chlorobenzylidene)thiourea. The purification of organic products from crude products using chromatographic techniques. The product is analysed the nature of the product with the aid of FT-IR, 1H-NMR and 13C-NMR. Further, to estimate the optimum reaction condition for the catalytic ability of the HPV supported on activated clay using condensation reaction of thiourea with 4-chlorobenzaldehyde.
\end{abstract}

Keywords: Heteropoly acid, Natural clay, Thiourea, (1E,3Z)-1,3-bis(4-chlorobenzylidene)thiourea.

\section{INTRODUCTION}

Heteropolyoxometalates (HPOM) having Keggin and Wells-Dawson-type structure has potential applications in various fields. They are used as homogeneous catalysts, heterogeneous catalysts, electro catalysts and photo catalysts for the synthesis of variety of organic compounds.[1-6] Heteropoly acids [HPV] were used in acid-catalysed reactions due to their strong Bronsted acidity. Clays form flat hexagonal sheets similar to the micas. Clay minerals are very common in fine grained sedimentary rocks such as shale, mudstone, and siltstone and in fine grained metamorphic slate and phyllite.[7, 8] The advantages of purified clay are natural availability, low cost and ease use in organic reactions. Efforts to prevent pollution in the development of new drug compounds paved the way for "Green chemistry", which produced an array of improved methodologies, including the use of clays as chemical

Revised Manuscript Received on December 22, 2019.

* Correspondence Author

K. Selvakumar, Nanomaterials Laboratory, Department of Chemistry, International Research Centre, Kalasalingam Academy of Research and Education (Deemed to be University), Krishnankoil - 626126, India. Email: selvachemistk@gmail.com

A. Raja , Multifunctional Materials Laboratory, Department of Physics, International Research Centre, Kalasalingam Academy of Research and Education (Deemed to be University), Krishnankoil - 626126, India. Email: rajaannamalai88@gmail.com

M. Arunpandian, Nanomaterials Laboratory, Department of Chemistry, International Research Centre, Kalasalingam Academy of Research and Education (Deemed to be University), Krishnankoil - 626126, India. Email: arunpandiantt126@gmail.com

P. Sami*, Department of Chemistry, V.H.N. Senthikumara Nadar College (Autonomous), Virudhunagar-626001, India. Email: samirishi2614@gmail.com

M. Swaminathan*, Nanomaterials Laboratory, Department of Chemistry, International Research Centre, Kalasalingam Academy of Research and Education (Deemed to be University), Krishnankoil - 626126, India. Email: m.swaminathan@klu.ac.in

catalysts.[9] Acidic properties of solid heteropolyacids (HPVs) made them useful versatile acid catalysts. They are usually solids that are insoluble in non-polar solvents but highly soluble in polar ones. They are more active than conventional inorganic and organic acids for various reactions in solution. $[10,11]$

It was reported that urea and thiourea derivatives showed a broad spectrum of biological activities such as anti-HIV, antiviral, HDL- elevating antibacterial, analgesic properties.[12-15] 1, 3- disubstituted urea / thiourea derivatives are known for their antiproliferative activity against a panel of human tumor cell lines.[16] Many thiourea derivatives have been known to posses fungicidal and pesticidal action and several others have been reported to exhibit anti tubercular, anti-fungal, insecticidal and acaracidal activity.[17] Most of the derivatives of urea and thiourea are derived through condensation types of reactions with aromatic aldehydes and phenols / naphthols.[18] This work aims to utilize HPV supported activated natural clay as catalyst for the condensation reaction of thiourea and 4-chlorobenzaldehyde to form (1E, 3Z)-1,3-bis(4-chlorobenzylidene)thiourea.

\section{EXPERIMENTAL}

\section{Materials and methods}

Thiourea, 4-chlorobenzaldehyde and $\beta$-naphthol obtained from Sigma Aldrich were used as such. HPV supported activated natural clay catalysts (HPVAC) were prepared and characterized as reported earlier.[18] FT-IR spectra were recorded in IR Affinity-Fourier Transform Infra Red Spectrophotometer as $\mathrm{KBr}$ disks. ${ }^{1} \mathrm{H}-\mathrm{NMR}$ and ${ }^{13} \mathrm{C}-\mathrm{NMR}$ were recorded from Bruker NMR $300 \mathrm{MHz}$, instrument by dissolving the samples in $\mathrm{CDCl}_{3}$.

\section{Synthesis of (1E,3Z)-1,3-bis(4-chlorobenzylidene)} thiourea

A mixture of 4-chlorobenzaldehyde (1 mmol), thiourea (1 mmol), HPVAC $(0.08 \mathrm{~g})$ and 1,2-dichloroethane $(10 \mathrm{~mL})$ was heated under reflux for 4 hours. The progress of the reaction was monitored by TLC (ethylacetate / dichloromethane in 7:3 ratio). After the completion of the reaction the HPVAC was removed by filtration. The filtrate containing solvent was evaporated in water bath to get a yellow solid which was washed with water, for the removal of un-reacted thiourea. Further the product was purified by column chromatography (Petroleum ether / Ethylacetate 9:1 ratio). 
The catalyst was recovered by washing it thoroughly with dichloromethane and dried in an air oven at $120{ }^{\circ} \mathrm{C}$ for about an hour.
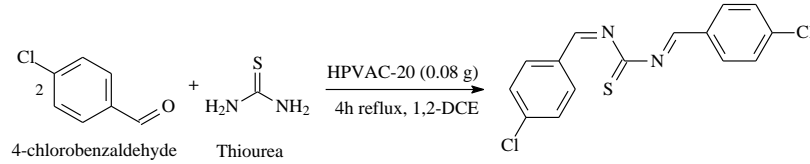

(1E,3Z)-1,3-bis(4-chlorobenzylidene) ourea

(80\% Yield)

Scheme 1. Synthesis of (1E,3Z)-1,3-bis(4-chlorobenzylidene)thiourea.

\section{RESULTS AND DISCUSSION}

\section{Catalytic efficiency of HPVAC}

One-pot three-component condensation of 4-chlorobenzaldehyde, $\beta$-naphthol and thiourea in the presence of HPVAC-20 catalyst using 1,2-dichloroethane as solvent was carried out. $1 \mathrm{mmol}$ of each of the reactants were mixed with $0.08 \mathrm{~g}$ of HPVAC-20 in $10 \mathrm{~mL}$ of 1,2-dichloroethane (1,2-DCE). The mixture was heated under reflex for about $4 \mathrm{~h}$. According to reported literature,[19] the product of the reaction was assumed to be 1-(4-chlorophenyl)-1,2-Dihydro-3H-naphtho[1,2-e]

[1,3] oxazine-3-thione. But in the present attempt instead of that, a yellow colour product was obtained with $85 \%$ yield (Scheme 2).

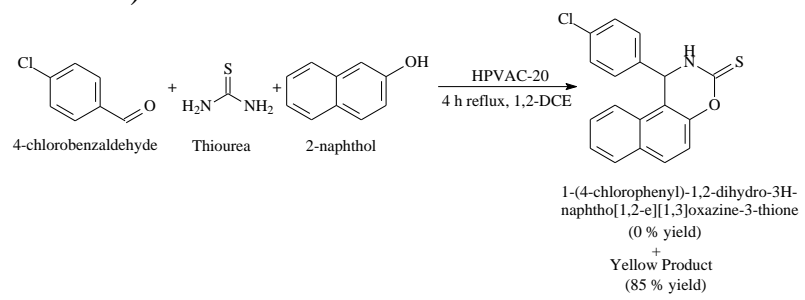

Scheme 2. Condensation of 4-chlorobenzaldehyde, $\beta$-naphthol and

$$
\text { thiourea }
$$

Next, the reaction was carried out under the same condition in the absence of thiourea (Scheme 3). After 4 hours of reaction, no more change of colour of the reaction mixture was noted. TLC analysis (Ethyl acetate / Dichloromethane, 7:3) of the reaction mixture also gave only two spots characteristics of the reactants 4-chlorobenzaldehyde and $\beta$-naphthol (Scheme 2). Therefore it is concluded that there is no reaction between 4-chlorobenzaldehyde and $\beta$-naphthol under the present experimental conditions.

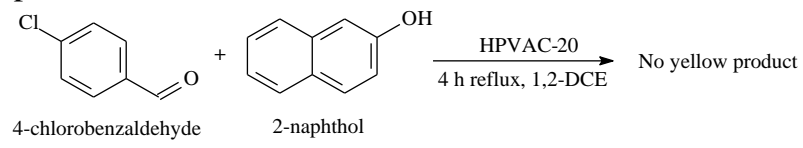

Scheme 3. Condensation of 4-chlorobenzaldehyde and $\beta$-naphthol

Further the reaction was carried out under the same condition. This time $\beta$-naphthol was removed. After 4 hours of reaction, a yellow colour product was obtained. TLC analysis (Ethyl acetate / Dichloromethane, 7:3) of the reaction mixture showed one spots characteristics of the new yellow product (Scheme 4). Therefore it is concluded that under the present experimental condition both 4-chlorobenzaldehyde and thiourea condensed together to give a yellow colour product.

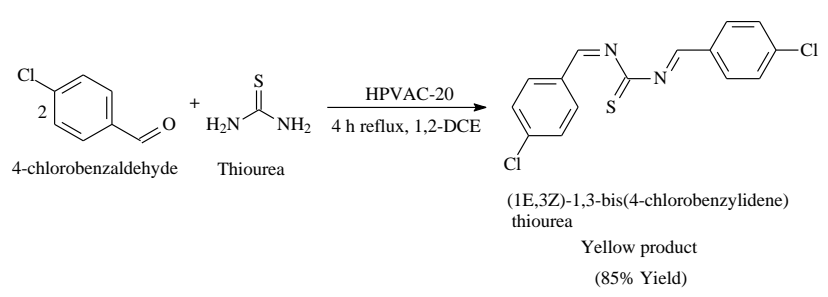

Scheme 4. Condensation of 4-chlorobenzaldehyde and thiourea

\section{The yellow product analysis}

There are five possible products during the course of the reaction. The possible reactions for the present case are explained with the help of Scheme 5. According to this the possible products are

I. (4-chlorophenyl)(hydroxyl) methyl carbamimidothiate

II. 1,1'-((4-chlorophenyl)methylene)bis(thiourea)

III. (Z)-1-(4-chlorobenzylidene)thiourea

IV. 7-chloroquinazoline-2(1H)-thione

V.(1E,3Z)-1,3-bis(4-chlorobenzylidene)thiourea

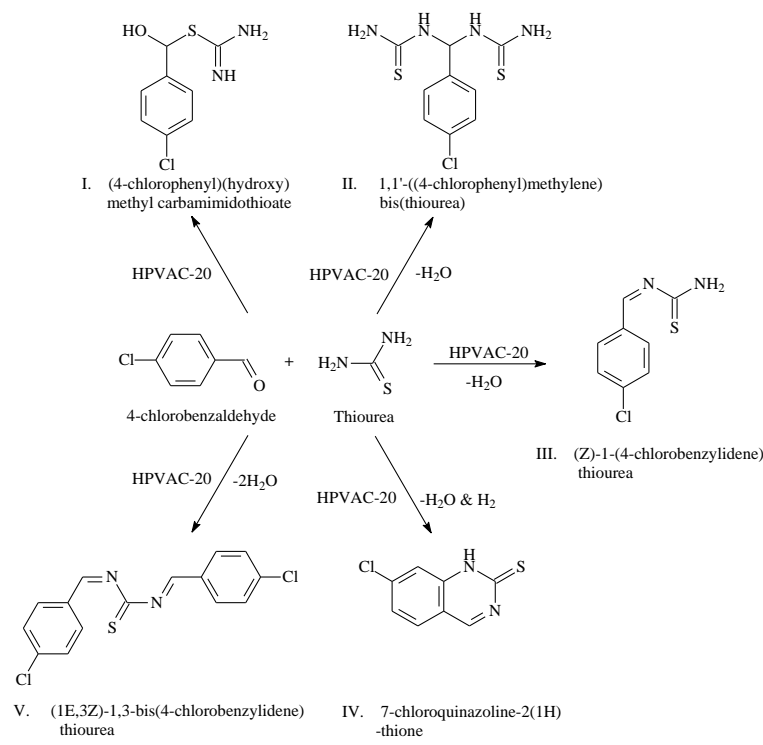

Scheme 5. Possible products during the course of the reaction.

Compound I was formed when 4-chlorobenzaldehyde, thiourea and para-toluenesulphonic acid were refluxed in toluene for 24 h.[20] Compound I contains free -OH group. Therefore one can expect band around $3650-3590 \mathrm{~cm}^{-1}$ in the FT-IR spectrum of the product. In this case the FT-IR (Fig. 1) of the yellow product did not show the characteristic band and therefore this product is ruled out.

If a water molecule is removed by the condensation [21] of two molecules of thiourea with a molecule 4-chlorobenzaldehyde the possible product is compound II. This compound has free $\mathrm{NH}_{2}$ group and therefore one can expect characteristic FT-IR band at $3367 \mathrm{~cm}^{-1}$ and ${ }^{1} \mathrm{H}-\mathrm{NMR}$ peak (Fig. 15) at $6.34 \delta(\mathrm{S}, 1 \mathrm{H})$. Absence of these features for the present product ruled out compound II as the possible product.

Currently, there is no report [22] on the successful synthesis of compound III and IV using aromatic aldehyde and thiourea as substrates. Therefore, compound III and IV are ruled out as possible products. Further the FT-IR, ${ }^{1} \mathrm{H}-\mathrm{NMR}$ and ${ }^{13} \mathrm{C}-\mathrm{NMR}$ data are favorable for the compound $\mathrm{V}$ as product of the present condensation. 
(1E,3Z)-1,3-bis(4-chlorobenzylidene)thiourea is formed by the condensation of 4-chlorobenzaldehyde with thiourea. It is a Schiff base. Structural elucidation of the compound using spectral technique is explained as follows.

FT-IR

\section{(1E,3Z)-1,3-bis(4-chlorobenzylidene)thiourea}

The FT-IR spectrum

(1E,3Z)-1,3-bis(4-chlorobenzylidene)thiourea is given as Fig.1. The spectral features are analysed with the help of reported literature.[17, 23] The FT-IR spectral bands at 2926 $\mathrm{cm}^{-1}$ and $1620 \mathrm{~cm}^{-1}$ respectively are attributed to $\mathrm{v}(\mathrm{C}-\mathrm{H})$ and $v(\mathrm{C}=\mathrm{N})$ stretching vibrations. The bands at $1591 \mathrm{~cm}^{-1}, 1544$ $\mathrm{cm}^{-1}$ and $1255 \mathrm{~cm}^{-1}$ are attributed due to $v$ (Aromatic C-C) and $v(\mathrm{C}=\mathrm{S})$ stretching vibrations. The FT-IR spectral data of compound $\mathrm{V}$ along with the same for thiourea and 4-chlorobenzaldehyd are collected in Table 1 for the sake of comparison.

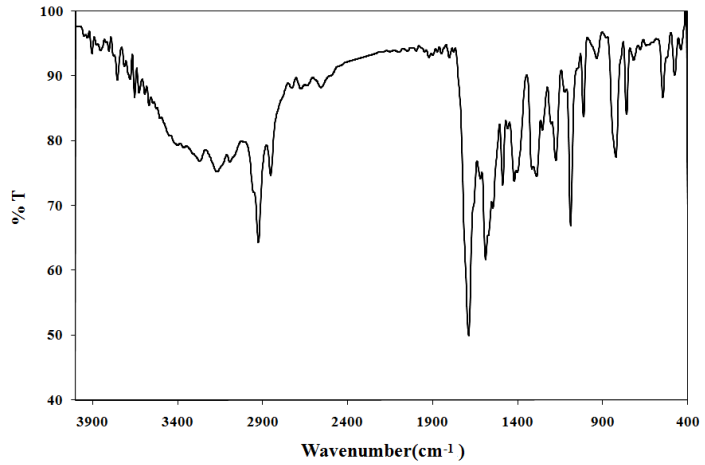

Fig. 1. The FT-IR spectrum of

(1E,3Z)-1,3-bis(4-chlorobenzylidene)thiourea recorded as $\mathrm{KBr}$ pellet

Table 1. The FT-IR spectrum data of 4-chlorobenzaldehyde, thiourea and (1E,3Z)-1,3-bis(4-chlorobenzylidene)thiourea

\begin{tabular}{|c|c|c|c|c|}
\hline $\begin{array}{c}\text { S. } \\
\text { No. }\end{array}$ & $\begin{array}{c}\text { Functional } \\
\text { groups }\end{array}$ & $\begin{array}{c}\text { 4-chloro- } \\
\text { benzaldehyde } \\
\left(\mathrm{cm}^{-1}\right)\end{array}$ & $\begin{array}{c}\text { Thiourea } \\
\left(\mathbf{( m}^{-1}\right)\end{array}$ & $\begin{array}{c}\text { (1E,3Z)-1,3-bis(4- } \\
\text { chlorobenzylidene)thiourea } \\
\left(\mathbf{c m}^{-1}\right)\end{array}$ \\
\hline 1. & $-\mathrm{NH}_{2}$ group & -- & 3367 & -- \\
\hline 2. & $-\mathrm{C}-\mathrm{H}$ group & --- & --- & 2926 \\
\hline 3. & $\begin{array}{c}\text { Aldehyde } \\
(\mathrm{C}=\mathrm{O}) \text { group }\end{array}$ & 1695 & --- & \\
\hline 4. & $\begin{array}{c}\text { Aromatic C-C } \\
\text { group }\end{array}$ & 1590 & --- & 1591,1544 \\
\hline 5. & $>\mathrm{C}=\mathrm{S}$ group & --- & 1195 & 1255 \\
\hline 6. & $>\mathrm{C}=\mathrm{N}$ group & --- & --- & 1620 \\
\hline
\end{tabular}

\section{${ }^{1}$ H-NMR analysis}

The proton NMR spectrum of (1E,3Z)-1,3-bis(4-chlorobenzylidene)thiourea is given Fig. 2 . The chemical shift values are collected in Table 2 along with possible assignment.

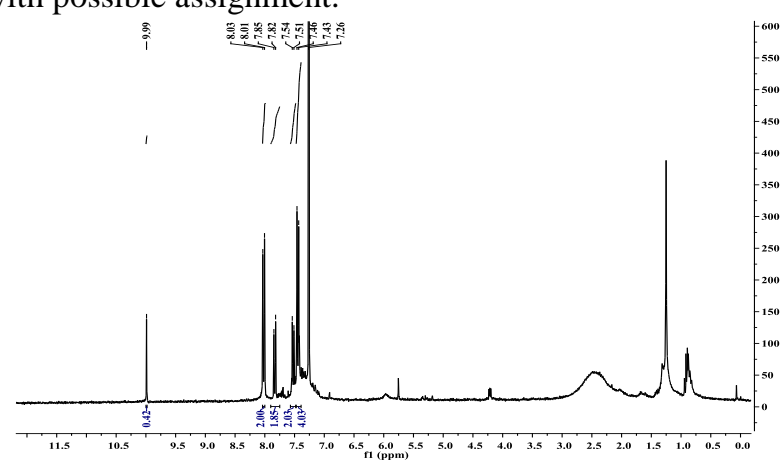

Fig. 2. ${ }^{1} \mathrm{H}-\mathrm{NMR}$ spectrum of (1E,3Z)-1,3-bis(4chlorobenzylidene)thiourea in $\mathrm{CDCl}_{3}$

Table 2. ${ }^{1} \mathrm{H}-\mathrm{NMR}$ data for (1E,3Z)-1,3-bis(4-chlorobenzylidene) thiourea

\begin{tabular}{|c|c|c|c|}
\hline S. No & Multiplicity & 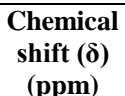 & $\begin{array}{c}\text { No. of } \\
\text { Hydrogen }\end{array}$ \\
\hline 1. & Doublet $(\mathrm{HC}=\mathrm{N})$ & 8.02 & $2 \mathrm{H}$ \\
\hline 2. & Doublet & 7.84 & $2 \mathrm{H}$ \\
\hline 3. & Doublet & 7.53 & $2 \mathrm{H}$ \\
\hline 4. & Doublet & 7.45 & $4 \mathrm{H}$ \\
\hline
\end{tabular}

${ }^{13}$ C-NMR analysis

${ }^{13} \mathrm{C}-\mathrm{NMR}$

spectrum

of

(1E,3Z)-1,3-bis(4-chlorobenzylidene)thiourea recorded in $\mathrm{CDCl}_{3}$ solvent is given in Fig. 3. The NMR data are collected in Table 3.

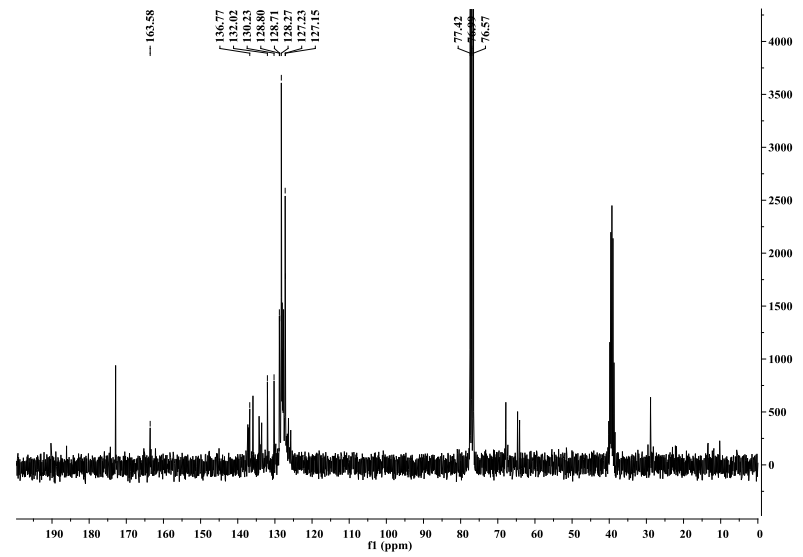

Fig. 3. ${ }^{13} \mathrm{C}$-NMR spectrum of (1E,3Z)-1,3-bis(4-chlorobenzylidene) thiourea in $\mathrm{CDCl}_{3}$

Table 3. ${ }^{13} \mathrm{CNMR}$ data for (1E,3Z)-1,3-bis(4-chlorobenzylidene) thiourea

\begin{tabular}{|c|c|c|}
\hline S. No & $\begin{array}{c}\text { Chemical shift }(\boldsymbol{\delta}) \\
(\mathbf{p p m})\end{array}$ & Carbon \\
\hline 1. & 163.58 & $(-\mathrm{HC}=\mathrm{N})$ \\
\hline 2. & 136.77 & Aromatic C \\
\hline 3. & 132.02 & Aromatic C \\
\hline 4. & 130.23 & Aromatic C \\
\hline 5. & 128.80 & Aromatic C \\
\hline
\end{tabular}

Influence of different catalysts and different solvents

Two-component condensation of 4-chlorobenzaldehyde and thiourea under reflux conditions for $4 \mathrm{~h}$ using different acid catalysts in various solvent systems such as 1,2-dichloroethane, dichloromethane and toluene was carried out. The results are depicted in Table 4.

Table 4.

Effect of different catalysts and solvents

\begin{tabular}{|c|l|l|c|c|}
\hline $\begin{array}{c}\text { S. } \\
\text { No }\end{array}$ & \multicolumn{1}{|c|}{ Catalyst } & \multicolumn{1}{|c|}{ Solvent } & $\begin{array}{c}\text { Reactio } \\
\text { n time } \\
\text { (reflex) } \\
\text { (h) }\end{array}$ & $\begin{array}{c}\text { \% } \\
\text { of } \\
\text { yiel } \\
\text { d }\end{array}$ \\
\hline 1. & No catalyst & 1,2-dichloroethane & 4 & 0 \\
\hline 2. & Acetic acid & 1,2-dichloroethane & 4 & 40 \\
\hline 3. & Acetic acid & Dichloromethane & 4 & 32 \\
\hline 4. & Acetic acid & Toluene & 4 & 45 \\
\hline 5. & $\mathrm{H}_{3}\left[\mathrm{PW}_{12} \mathrm{O}_{40}\right]$ & 1,2-dichloroethane & 4 & 26 \\
\hline 6. & $\mathrm{H}_{3}\left[\mathrm{PW}_{12} \mathrm{O}_{40}\right]$ & Dichloromethane & 4 & 29 \\
\hline 7. & $\mathrm{H}_{3}\left[\mathrm{PW}_{12} \mathrm{O}_{40}\right]$ & Toluene & 4 & 31 \\
\hline 8. & $\mathrm{H}_{4}\left[\mathrm{PVW}_{11} \mathrm{O}_{40}\right]$ & 1,2-dichloroethane & 4 & 65 \\
\hline
\end{tabular}

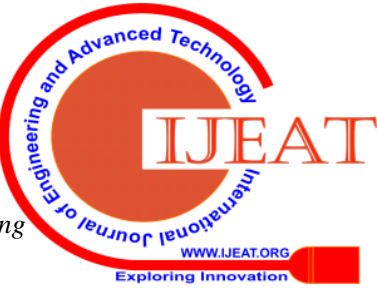


Catalytic Efficiency of Heteropoly 11-Tungsto-1-Vanadophosphoric Acid - Activated Clay in the Condensation Reaction of Thiourea with 4-Chlorobenzaldehyde

\begin{tabular}{|c|l|l|c|c|}
\hline 9. & $\mathrm{H}_{4}\left[\mathrm{PVW}_{11} \mathrm{O}_{40}\right]$ & Dichloromethane & 4 & 52 \\
\hline 10. & $\mathrm{H}_{4}\left[\mathrm{PVW}_{11} \mathrm{O}_{40}\right]$ & Toluene & 4 & 59 \\
\hline 11. & HPVAC-10 & 1,2-dichloroethane & 4 & $\mathbf{8 0}$ \\
\hline 12. & HPVAC-10 & Dichloromethane & 4 & $\mathbf{7 0}$ \\
\hline 13. & HPVAC-10 & Toluene & 4 & $\mathbf{7 3}$ \\
\hline 14. & Activated clay & 1,2-dichloroethane & 4 & 0 \\
\hline 15. & $\mathrm{H}_{5}\left[\mathrm{PV}_{2} \mathrm{~W}_{10} \mathrm{O}_{40}\right]$ & 1,2-dichloroethane & 4 & 52 \\
\hline 16. & $\mathrm{H}_{5}\left[\mathrm{PV}_{2} \mathrm{~W}_{10} \mathrm{O}_{40}\right]$ & Dichloromethane & 4 & 41 \\
\hline 17. & $\mathrm{H}_{5}\left[\mathrm{PV}_{2} \mathrm{~W}_{10} \mathrm{O}_{40}\right]$ & Toluene & 4 & 48 \\
\hline 18. & $\mathrm{~K}_{7} \mathrm{H}_{2}\left[\mathrm{BCoW}_{11} \mathrm{O}_{40}\right]$ & 1,2-dichloroethane & 4 & 25 \\
\hline 19. & $\mathrm{~K}_{7} \mathrm{H}_{2}\left[\mathrm{BCoW}_{11} \mathrm{O}_{40}\right]$ & Dichloromethane & 4 & 20 \\
\hline 20. & $\mathrm{~K}_{7} \mathrm{H}_{2}\left[\mathrm{BCoW}_{11} \mathrm{O}_{40}\right]$ & Toluene & 4 & 24 \\
\hline
\end{tabular}

It clearly indicates that the catalyst HPVAC-10 in the presence of 1,2-dichloroethane gave maximum yield among the given combination.

\section{Effect of catalyst loading}

Under the above optimized reaction solvent system the reaction was tried with catalyst with different loadings of HPV say $10 \%, 20 \%$ and $30 \%$. The catalysts are respectively denoted as HPVAC-10, HPVAC-20 and HPVAC-30 (Table $5)$.

Table 5. Variation of percentage of HPV loading clay catalyst

\begin{tabular}{|c|c|c|c|c|}
\hline $\begin{array}{l}\text { S. } \\
\text { No }\end{array}$ & $\begin{array}{c}\text { \% of HPV } \\
\text { loading in clay } \\
\text { catalyst }(\%)\end{array}$ & $\begin{array}{c}\text { Weight of } \\
\text { catalyst }(\mathrm{g})\end{array}$ & $\begin{array}{c}\text { Reaction time } \\
\text { (reflex) (h) }\end{array}$ & $\begin{array}{c}\text { \% of } \\
\text { yield }\end{array}$ \\
\hline 1. & 10 & 0.08 & 4 & 80 \\
\hline 2. & 20 & 0.08 & 4 & $\mathbf{8 5}$ \\
\hline 3. & 30 & 0.08 & 4 & 86 \\
\hline
\end{tabular}

Activated clay with $20 \%$ HPV loading was found to be more efficient than the other two combinations. The optimization studies with varying amount of HPVAC-20 from 0.02 to 0.12 $\mathrm{g}$ was performed. In these trials $0.08 \mathrm{~g}$ of HPVAC-20 gave maximum yield of the product. Further the optimum time required for the completion of the reaction was also evolved and it is found to be $4 \mathrm{~h}$.

Optimization studies recommends $0.08 \mathrm{~g}$ HPVAC-20 as catalyst in the presence of 1,2-dichloroethane medium under reflux condition for $4 \mathrm{~h}$ in order to get the maximum yield for the condensation of 4-chlorobenzaldehyde and thiourea to get (1E,3Z)-1,3-bis(4-chlorobenzylidene)thiourea (Scheme 1).

\section{CONCLUSION}

Synthesis of (1E, 3Z)-1,3-bis(4-chlorobenzylidene)thiourea by the condensation reaction of thiourea and 4-chlorobenzaldehyde in the presence of HPVAC catalyst produced high yield under heterogeneous condition. The product was identified as (1E,3Z)-1,3-bis(4-chlorobenzylidene)thiourea by FTIR and ${ }^{1} \mathrm{H}$ and ${ }^{13} \mathrm{C}-\mathrm{NMR}$. Further the optimum conditions for the catalytic reaction were reported.

\section{ACKNOWLEDGEMENT}

The author, K.S. acknowledges Kalasalingam Academy of Research and Education for providing research fellowship and necessary facilities.

\section{REFERENCES}

[1] Pope, M.T., Muller, A. Introduction to polyoxometalate chemistry: from topology via self-assembly to applications, Polyoxometalate Chemistry from Topology via Self-Assembly to Applications, Springer, Dordrecht, 2001, 1-6.

[2] Yamase. T, Pope. M. T, Polyoxometalate Chemistry for Nano-Composite Design, Kluwer Academic/ Plenum Publishers, 2002.

[3] Katsoulis, D.E. A survey of applications of polyoxometalates, Chem. Rev., 1998, 98, 359-388.

[4] Heravi, M.M., Sadjadi, S. Recent developments in use of heteropolyacids, their salts and polyoxometalates in organic synthesis, J. Iran. Chem. Soc., 2009, 6, 1-54.

[5] Firouzabadi, H., Jafari, A.A. Heteropoly acids, their salts and polyoxometalates as heterogenous, efficient and eco-friendly catalysts in organic reactions: Some recent advances, J. Iran. Chem. Soc., 2005, 2, 85-114.

[6] Kozhevnikov, I. Catalysis by heteropoly acids and multicomponent polyoxometalates in liquid-phase reactions, Chem. Rev., 1998, 98, 171-198.

[7] Timofeeva, M.N., Matrosova, M.M., Reshetenko, T.V., Avdeeva, L.B., Budneva, A.A., Ayupov, A.B., Paukshtis, E.A., Chuvilin, A.L., Volodin, A.V., Likholobov, V.A. Filamentous carbons as a support for heteropoly acid, J. Mol. Catal. A: Chem., 2004, 211, 131-137.

[8] Haber, J., Pamin, K., Matachowski, L. Mucha, D. Catalytic performance of the dodecatungstophosphoric acid on different supports, Appl. Catal. A, 2003, 256, 141-152.

[9] Nagendrappa, G. Organic synthesis using clay catalysts, Resonance, 2002, 7, 64-77.

[10] Kozhevnikov. I., Derouane. E, Catalysis for Fine Chemical Synthesis, Catalysis by Polyoxometalates 2, Eds., Wiley, New York, 2002.

[11] Drago, R.S., Dias, J.A., Maier, T. An acidity scale for bronsted acids including $\mathrm{H}_{3} \mathrm{PW}_{12} \mathrm{O}_{40}$, J. Am. Chem. Soc., 1997, 119, 7702-7710.

[12] Struga, M., Kossakowski, J., Ke Dzierska, E., Fidecka, S., Stefanska, J. Synthesis and pharmacological activity of urea and thiourea derivatives of 4-azatricyclo [5.2. 2.02, 6] undec-8-ene-3, 5-dione, Chem. Pharm. Bull., 2007, 55, 796-799.

[13] Venkatachalam, T.K.., Mao, C., Uckun, F.M. Effect of stereochemistry on the anti-HIV activity of chiral thiourea compounds, Bioorg. Med. Chem., 2004, 12, 4275-4284.

[14] Bloom, J.D., Dushin, R.G., Curran, K.J., Donahue, F., Norton, E.B., Terefenko, E., Jonas, T.R., Ross, A.A., Feld, B., Lang, S.A., Di Grandi, M.J., Thiourea inhibitors of herpes viruses. Part 2 N-Benzyl-N'-arylthiourea inhibitors of CMV, Bioorg. Med. Chem. Lett., 2004, 14, 3401-3406.

[15] Lee, J., Lee, J., Kang, M., Shin, M., Kim, J.M., Kang, S.U., Lim, J.O., Choi, H.K., Suh, Y.G., Park, H.G. Oh, U., Kim, H.D., Park, Y.H., Ha H.J., Kim, Y.H., Toth, A., Wang, Y., Tran, R., Pearce, L.V., Lundberg, D. J., Blumberg, P.M N-(3-Acyloxy-2-benzylpropyl)-N`-[4-(methylsulfonylamino)benzyl] thiourea analogues: Novel potent and high affinity antagonists and partial antagonists of the vanilloid receptor, J. Med. Chem., 2003, 46, 3116-3126.

[16] Phanikumar, G.K., Ganga Rao Battu, Lova raju, N., Kotha, S. Isolation and Evaluation of Tamarind Seed Polysaccharide being used as a Polymer in Pharmaceutical Dosage Forms, Res. J. Pharma Res. Devel., 2011, 2, 274-290.

[17] Al-Obaidi, O.H. Synthesis, Characterization and Theoretical Treatment of Sandwich Schiff Base Complexes Derived from Urea and Thiourea with Some Transition Metals and Study of Its Biological Activity, J. Appl. Chem., 2012, 1, 352-359.

[18] Selvakumar, K., Shanmugaprabha, T., Annapoorani, R., Sami, P. One-pot three-component synthesis of bis (indolyl) methanes under solvent-free condition using heteropoly-11-tungsto-1 vanadophosphoric acid supported on natural clay as catalyst, Synth. Commun., 2017, 47, 913-927.

[19] Kumar, A., Saxena, A., Dewan, M., Arnab De., Mozumdar, S. Recyclable nanoparticulate copper mediated synthesis of naphthoxazinones in PEG-400: a green approach, Tetrahedron Lett., 2011, 52, 4835-4839.

[20] Taylor, J. The interaction of aldehydes or ketones and thiocarbamides in the presence of acids. Part II, J. Chem. Soc. Trans., 1922, 121, 2267- 2272 
[21] Kappe, C.O. A reexamination of the mechanism of the Biginelli dihydropyrimidine synthesis. Support for an N-Acyliminium ion intermediate1," The Journal of Organic Chemistry, 62 (1997) pp. 7201-7204.

[22] Zhi-Liang Shen, Xiao-Ping Xu, and Shun-Jun Ji, "Bronsted basecatalyzed one-pot three-component Biginelli-type reaction: An efficient synthesis of 4, 5, 6-triaryl-3, 4-dihydropyrimidin-2 (1 H)one and mechanistic study, J. Org. Chem., 2010, 75, 1162-1167.

[23] Jamila, K., Wajid, R., Bakhtiar, M., Danish, M. Biologically active organotin (IV) schiff base complexes, J. Iran. Chem. Soc., 2010, 7, 495-499.

\section{AUTHORS PROFILE}

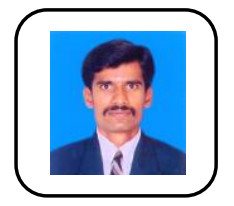

Dr. K. Selvakumar is a Postdoctoral Fellow at Nanomaterials Laboratory, Department of Chemistry, Kalasalingam Academy of Research and Education (Deemed to be University), Krishnankoil, India. Now, he is working on the Postdoctoral Researcher, Institute of Microstructure and Property of Advanced Materials, Beijing University of Technology, Ping Le Yuan, Chaoyang, Beijing, China. He has published 21 papers in peer-reviewed journal on the kinetics, organic synthesis and photocatalysis.

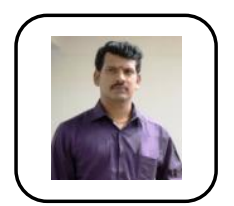

Dr. A. Raja is a Postdoctoral Fellow at Multifunctional Materials Laboratory, Department of Physics, Kalasalingam Academy of Research and Education (Deemed to be University), Krishnankoil, India. He has working on the field of electrochemistry, kinetics and photocatalysis.

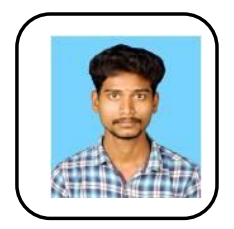

M. Arunpandian is a research scholar at Nanomaterial Laboratory, Department of Chemistry, International Research Centre, Kalasalingam Academy of Research and Education (Deemed to be University), Krishnankoil, India. He is working in the area materials Characterization, waste water purification and Photocatalysis.

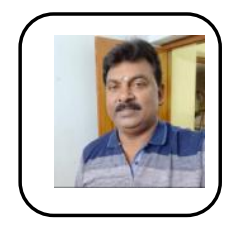

Dr. P. Sami is Associate Professor in Department of Chemistry, V.H.N. Senthikumara Nadar College (Autonomous), Virudhunagar-626001, India. His area of research is the kinetics, organic synthesis and photocatalysis.

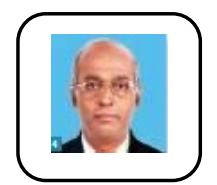

Dr. M. Swaminathan, Professor in Department of Chemistry, International Research Centre, Kalasalingam Academy of Research and Education (Deemed to be University), Krishnankoil, India. He completed his B.Sc., at Thiagaraja College, Madurai and M.Sc., from Annamalai University, Annamalai nagar. He received his Ph.D degree from IIT, Kanpur. He has published 206 papers in peer-reviewed journal on the Photo-Electro catalysis and Environmental energy applications. He is the fellow of Royal Society of Chemistry and he achieved more number of awards. 